\title{
Monitoring a widespread bacterial group: in situ detection of planctomycetes with 165 rRNA-targeted probes
}

\author{
Alexander Neef, ${ }^{1}+$ Rudolf Amann, ${ }^{1,2}$ Heinz Schlesner ${ }^{3}$ \\ and Karl-Heinz Schleifer ${ }^{1}$ \\ Author for correspondence: Alexander Neef. Tel: +4964199 37373. Fax: +496419937359. \\ e-mail: alexander.neef@agrar.uni-giessen.de
}

\author{
1 Lehrstuhl für \\ Mikrobiologie, Technische \\ Universität München, \\ Arcisstr. 16, D-80290 \\ München, Germany \\ 2 Max-Planck-Institut für \\ Marine Mikrobiologie, \\ Celsiusstr. 1, D-28359 \\ Bremen, Germany \\ 3 Institut für Allgemeine \\ Mikrobiologie, Christian- \\ Albrechts-Universität Kiel, \\ Am Botanischen Garten \\ 1-9, D-24118 Kiel, Germany
}

The group of planctomycetes represents a separate line of descent within the domain Bacteria. Two phylum-specific 165 rRNA-targeted oligonucleotide probes for planctomycetes have been designed, optimized for in situ hybridization and used in different habitats to detect members of the group in situ. The probes, named PLA46 and PLA886, are targeting all or nearly all members of the planctomycete line of descent. Planctomycetes could be detected in almost all samples examined, e.g. a brackish water lagoon, activated sludge, and other wastewater habitats. In situ probing revealed quite uniform morphology and spatial arrangement of the detected cells but profound differences in abundance ranging from less than $0.1 \%$ to several percentage of the total cells. Single coccoid cells with diameters between 1 and $2.5 \mu \mathrm{m}$ were dominating in most samples with the exception of the lagoon, in which rosettes of pear-shaped cells were abundant. The planctomycetes showed generally no hybridization signals with the bacterial probe EUB338, which is in accordance with base changes in their 165 rRNA sequences. A discrete ultrastructure of planctomycete cells was suggested by double staining with rRNA-targeted probes and the DNA-binding dye 4',6diamidino-2-phenylindole (DAPI). The probe-conferred fluorescence was distributed in a ring-shaped manner around a central DAPI spot. The two probes developed extend the existing set of group-specific rRNA-targeted probes and help to elucidate the basic composition of bacterial communities in a first step of differential analysis. In situ hybridization of environmental samples indicated widespread presence of planctomycetes in different ecosystems.

Keywords: planctomycetes, rRNA-targeted probes, fluorescence in situ hybridization (FISH), in situ identification

\section{INTRODUCTION}

Planctomycetes are aerobic, Gram-negative, chemoheterotrophic bacteria with mostly spherical, ovoid or pear-shaped cell morphology. They share some unique

\footnotetext{
†Present address: Institut für Angewandte Mikrobiologie, Justus-Liebig Universităt Giessen, Senckenbergstr. 3, D-35390 Giessen, Germany.

Abbreviations: $\mathrm{BOD}_{5}$, biological oxygen demand within $5 \mathrm{~d}$ incubation; DAPI, 4',6-diamidino-2-phenylindole; FLUOS, 5(6)-carboxy-fluorescein- $N$ hydroxysuccinimide ester; TAMRA, 5(6)-carboxy-tetramethylrhodamine- $N$ hydroxysuccinimide ester; WWTP, wastewater treatment plant.
}

characters that distinguish them from other bacteria, most importantly the lack of peptidoglycan in their cell walls and the budding type of reproduction. Some members have typical acellular appendages. Main ecological features of the group have been recently reviewed (Fuerst, 1995). Pure cultures have been isolated from diverse aquatic habitats such as freshwater lakes, brackish water and sea water as well as from a hot spring (Schmidt, 1978; Schlesner, 1986, 1994; Giovannoni et al., 1987). So far, four genera, Planctomyces, Pirellula, Gemmata and Isosphaera, are validly described (Staley et al., 1992; Holt et al., 1994). A new 
order, Planctomycetales, was proposed (Schlesner \& Stackebrandt, 1986) that encompasses all four genera.

Analysis of rRNA molecules demonstrated that this order comprises a separate line of descent within the domain Bacteria clearly separated from the other phyla (Stackebrandt et al., 1984; Woese, 1987). Their 16S rRNA sequences possess unique signatures. Other idiosyncrasies are shorter $5 \mathrm{~S}$ rRNA molecules in comparison to other bacterial lineages (Bomar et al., 1988) and unlinked $r r n$ operon structures detected in two members (Liesack \& Stackebrandt, 1989; Ward-Rainey et al., 1996). The four genera constitute distinct phylogenetic lineages within the phylum (Bomar et al., 1988; Staley et al., 1992). In a recent study on the phylogenetic position of 22 environmental isolates by $16 \mathrm{~S}$ rDNA sequence analysis, considerable diversity within the order Planctomycetales was shown. In fact, none of the newly studied strains was related to any previously described species at species level (Ward et al., 1995).

The members of the four genera possess typical cell shapes. On this basis they could be differentiated (Holt et al., 1994). Further differences exist regarding the type of cell aggregation, e.g. rosette formation for Planctomyces and Pirellula or as filaments of coccoid cells for Isosphaera pallida, and type of motility, such as gliding as described for I. pallida versus via flagellation for members of the other three genera.

Up to a few years ago planctomycetes had been supposed to be restricted to aquatic environments, since all known pure cultures have been isolated from habitats like freshwater or marine samples. In fact, even in 1992 in The Prokaryotes the group has been described as solely aquatic (Staley et al., 1992). Therefore, it was surprising when the first evidence for occurrence of planctomycetes in terrestrial habitats came in a study on $16 \mathrm{~S} \mathrm{rDNA}$ clone sequences from Australian soils (Liesack \& Stackebrandt, 1992). Later, further studies reporting the presence of planctomycete $16 \mathrm{~S}$ rDNA/rRNA sequences in different habitats, such as in marine snow from offshore seawater (DeLong et al., 1993), sludge from a sequencing batch reactor (Bond et al., 1995), marine sediments (Gray \& Herwig, 1996), silt-loam soils (Borneman et al., 1996; Lee et al., 1996) and in postlarvae from prawns (Fuerst et al., 1997), indicated that they are widely distributed. However, cloning approaches yield only sequence data without the possibility of acquiring additional information on the organisms. Up to now, isolation of a pure culture from any non-aquatic habitat has not been reported.

It was the goal of this study to develop rRNA-targeted oligonucleotide probes for the evaluation of the natural abundance of planctomycetes by in situ hybridization. Here we report the development, optimization and in situ application of two probes on the phylum level to address the question of how far distributed this group of organisms is in environmental habitats.

\section{METHODS}

Organisms and culture conditions. The following reference strains were used in this study: Gemmata sp. SCH633, Isosphaera sp. SCH394, Pirellula marina DSM $3645^{\mathrm{T}}$, Pirellula sp. SCH1, Pirellula sp. SCH140 [all obtained from the Institut für Allgemeine Mikrobiologie (IFAM) strain collection], Planctomyces limnophilus ATCC $43296^{\mathrm{T}}$, Brevibacterium linens DSM 20425 $5^{\mathrm{T}}$, Cellulomonas turbata LMG $4072^{\mathrm{T}}$, Chryseobacterium gleum LMG 8333, Comamonas testos-

Table 1. Sampling locations

\begin{tabular}{|c|c|c|}
\hline Brackish water lagoon & Size & Chemical characteristics \\
\hline Lake Albufera, south of Valencia, Spain & $\begin{array}{l}\text { Surface, } 2.2 \mathrm{~km}^{2} \text {; medium } \\
\text { depth, } 0.75 \mathrm{~m}\end{array}$ & Salinity, $0.2 \% ; \mathrm{pH}, 8-10$; hypereutrophic \\
\hline $\begin{array}{l}\text { Treatment plant location for } \\
\text { activated sludge samples }\end{array}$ & $\begin{array}{l}\text { Population } \\
\text { equivalents }\end{array}$ & $\begin{array}{c}\text { Type of wastewater and } \\
\text { plant processing }\end{array}$ \\
\hline Airolo, Ticino, Switzerland & About 10000 & Municipal; one biological stage \\
\hline Freising* & 110000 & $\begin{array}{l}\text { Municipal, dairy and brewery sewages; } \\
\text { one stage }\end{array}$ \\
\hline Grüneck* & 100000 & Mainly municipal; one stage \\
\hline Haag* & 3600 & Municipal; one stage \\
\hline München-Dietersheim, Germany & 1000000 & Mainly municipal sewage; two stages \\
\hline München-Großlappen, Germany & 1000000 & Mainly municipal; two stages \\
\hline Valencia-Pinedo, Spain & 650000 & Mainly municipal; one stage \\
\hline Other samples from WWTPs & Origin of sample & Type of processing \\
\hline Sand filter, München-Dietersheim & Sampling depth, $1.0 \mathrm{~m}$ & $\begin{array}{l}1.5 \text {-m-thick filter bed of } 2.5 \mathrm{~mm} \text { quartz grains; } \\
\text { removal of suspended solids }\end{array}$ \\
\hline Influent and effluent of Valencia-Pinedo & & \\
\hline
\end{tabular}

* These plants are located in the county of Upper Bavaria close to München. 
Table 2. Oligonucleotide probes

\begin{tabular}{|lllccc|}
\hline Name & OPD designation & & Sequence from 5' to $\mathbf{3}^{\prime}$ & Position $\dagger$ & Stringency $\neq$ \\
\hline PLA46 & S-P-Planc-0046-a-A-18 & GACTTGCATGCCTAATCC & $46-63$ & 30 & This study \\
PLA886 & S-P-Planc-0886-a-A-19 & GCCTTGCGACCATACTCCC & $886-904$ & $35 \$$ & This study \\
EUB338 & S-D-Bact-0338-a-A-18 & GCTGCCTCCCGTAGGAGT & $338-355$ & 0 & Amann et al. $(1990)$ \\
EUB008 & S-D-Bact-0008-a-A-19 & TGAGCCAGGATCAAACTCT & $8-26$ & 0 & Hicks et al. (1992) \\
\hline
\end{tabular}

* Standardized probe name according to proposal of Alm et al. (1996); OPD, oligonucleotide probe database.

† Target site in $16 \mathrm{~S}$ rRNA according to E. coli numbering (Brosius et al., 1981).

$\ddagger$ Amount of formamide $(\%, v / v)$ in hybridization buffer.

$\$$ Hybridization together with equimolar amount of competitor oligonucleotide cPLA886, 5' GCCTTGCGACCGTACTCCC 3’.

teroni LMG $1800^{\mathrm{T}}$ and Escherichia coli DSM $30083^{\mathrm{T}}$ (ATCC, American Type Culture Collection, Rockville, MD, USA; DSMZ, Deutsche Sammlung von Mikroorganismen und Zellkulturen, Braunschweig, Germany; LMG, Laboratorium voor Mikrobiologie, Universiteit Ghent, Belgium). Planctomycete strains were grown on the following solid media (18 g agar $~^{-1}$ ) as described by Schlesner (1994): PYGV for SCH394, M31 supplemented with peptone and yeast extract $\left(0.25 \mathrm{~g} \mathrm{l}^{-1}\right.$ of each) for ATCC $43296^{\mathrm{T}}$ and SCH633 and M13a for DSM $3645^{\mathrm{T}}, \mathrm{SCH} 1$ and SCH140. All other strains were cultivated as outlined in the respective catalogues of strains.

Cell fixation. Fixation with $4 \%(\mathrm{w} / \mathrm{v})$ paraformaldehyde and subsequent treatment was performed according to Amann et al. (1990). Cell material was collected either directly from solid media or from exponentially growing liquid cultures. It was resuspended in $200 \mu \mathrm{l}$ PBS $(130 \mathrm{mM} \mathrm{NaCl}, 10 \mathrm{mM}$ sodium phosphate buffer, $\mathrm{pH} 7 \cdot 4)$ and $600 \mu$ l fixative was added.

Samples. Characteristics of the investigated habitats are given in Table 1. Surface water was sampled from the brackish coastal lagoon (Aznar et al., 1991) as well as from inflow and outflow channels of one wastewater treatment plant (WWTP), mixed liquor from activated sludge basins and solid material from the sand filter bed. Liquid and solid samples were fixed immediately after sampling with paraformaldehyde solution and further processed as described by Wagner et al. (1993) and Neef et al. (1996), respectively.

Oligonucleotide probes. Probe sequences and target sites for the probes used in this study are displayed in Table 2. Oligonucleotides synthesized with a $5^{\prime}-\mathrm{C}_{6}$-aminolinker were purchased from MWG-Biotech. Labelling with the fluorochromes $5(6)$-carboxy-fluorescein- $N$-hydroxysuccinimide ester (FLUOS; Boehringer Mannheim) and 5(6)-carboxy-tetramethylrhodamine- $N$-hydroxysuccinimide ester (TAMRA; Molecular Probes) and subsequent purification of the oligonucleotide-dye conjugates were performed as described by Amann et al. (1990).

Hybridizations. Hybridizations were done on gelatin-coated glass slides with six wells for independent positioning of samples. Aliquots of fixed reference cells and environmental samples were spotted on single wells, air-dried and dehydrated by passing them through an ethanol series $(50,80$ and $96 \%$, $\mathrm{v} / \mathrm{v})$ for $3 \mathrm{~min}$ each. Hybridizations were performed in isotonically equilibrated humid chambers for $1.5 \mathrm{~h}$ at $46^{\circ} \mathrm{C}$. Hybridization buffer $(10 \mu \mathrm{l})$ containing $0.9 \mathrm{M} \mathrm{NaCl}, 20 \mathrm{mM}$ Tris $/ \mathrm{HCl}, \mathrm{pH} 8 \cdot 0,0 \cdot 01 \% \mathrm{SDS}$, the specific amount of formamide (Table 2) and $5 \mathrm{ng}$ FLUOS- or TAMRA-labelled probe $\mu^{-1}$ were applied on each well of the slide. Washing was achieved by immediate rinsing with $1 \mathrm{ml}$ prewarmed $\left(48^{\circ} \mathrm{C}\right)$ washing buffer followed by a $20 \mathrm{~min}$ immersion in washing buffer at $48^{\circ} \mathrm{C}$. The washing buffer contained $20 \mathrm{mM}$ Tris/ $\mathrm{HCl}, \mathrm{pH} 8 \cdot 0,0 \cdot 01 \%$ SDS and, depending on the hybridization stringency, between $0.056 \mathrm{M}$ and $0.9 \mathrm{M} \mathrm{NaCl}$. Subsequently, slides were rinsed with deionized water. After air-drying, slides were optionally counterstained with 4',6-diamidino-2phenylindole (DAPI) (see below) and embedded in Citifluor.

DAPI staining. Counterstaining with the DNA-binding dye DAPI (Boehringer Mannheim) was performed following the washing step of the hybridization protocol. Single wells on the slide were covered with $30 \mu \mathrm{l}$ DAPI solution $\left(1 \mu \mathrm{g} \mathrm{m} l^{-1}\right.$ in PBS) and incubated at room temperature for $10 \mathrm{~min}$ in the dark. After rinsing with water and air-drying the slide could be mounted in Citifluor.

Microscopy and documentation. Examination was done with a Zeiss Axioplan microscope (Carl Zeiss) equipped with Zeiss filter sets no. 09 and 15 and Chroma filter sets HQ-Cy 3 and HQ-FITC (Chroma) for probe-conferred and Zeiss filter set no. 01 for DAPI-conferred fluorescence. Photomicrographs were taken with a Kodak Ektachrome P1600 colour reversal film and a Kodak TMAX 400 black-and-white film. Exposure times were 5-15 s and 0.5-1 s for colour micrographs of probe-conferred and DAPI epifluorescence, respectively, and $60 \mathrm{~s}$ for the black-and-white micrographs.

Signal quantification. Fluorescence conferred by probes PLA46-TAMRA and PLA886-TAMRA to reference cells was quantified using a CCD camera (CF 15/2; Kappa) attached to the epifluorescence microscope and the fg-cell image analysis program (Captec), as described by Trebesius et al. (1994). Between 50 and 250 cells were analysed for each data point. Values of probe-conferred fluorescence intensities of each cell were divided by cell area to determine intensity values independent of cell size. Mean values of signal intensities were normalized relative to the signal of the probe EUB008-FLUOS to correct for the different contents of ribosomes in the reference strains. Sigmoidal fitting of melting curves was carried out using the graphics software Origin (version 3.5; Microcal Software).

\section{RESULTS AND DISCUSSION}

\section{Design of 165 rRNA-targeted probes}

Probe design was initially performed on the basis of about 3500 complete and partial $16 \mathrm{~S}$ rRNA sequences 
(a) PLA46

Probe sequence
Target sequence
Gemmata sp. strain SCH633
Chlamydia spp.
Sequences from clone libraries
Spirochaeta thermophila
Brevinema andersonii
Chryseobacterium gleum
Pyrobaculum islandicum
Majority of the spirochaetes

(b) PLA886

Probe sequence
Target sequence
Gemmata sp. strain SCH633
Brevibacterium linens
Holophaga foetida
Buchnera aphidicola
Desulfovibrio longus
Nitrospina gracilis
Blattabacterium spp.
Most actinomycetes
Bacillus spp.
Thermus spp.
Vibrio cholerae
Xanthomonas spp.
Escherichia coli
Comamonas testosteroni
Chlamydia spp.

3' - CCCTCATACCAGCGTTCCG - 5' 5' -GGGAGUAUGGUCGCAAGGC - 3 '

. . . . . . . . .

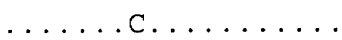

$\ldots \ldots c \ldots \ldots \ldots$

$\ldots \ldots \ldots \ldots \ldots$

$\ldots \ldots \ldots \ldots \ldots$

$\ldots \ldots \ldots \ldots \ldots \ldots$

$\ldots \ldots c \ldots \ldots \ldots$

$\ldots \ldots$. . . . . . . .

$\ldots \ldots$.........

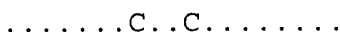

$\ldots \ldots C \ldots \ldots$. . .

$\ldots \ldots$......

$\ldots \ldots$. .....Au

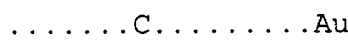

A.....C.C......G
Fig. 1. Difference alignments for probes PLA46 (a) and PLA886 (b). 16S rRNA sequences at the target sites of the probes are displayed for representative reference organisms. Upper-case letters indicate nucleotide changes leading to strong mismatches; lower-case letters indicate changes leading to weak mismatches. In (a) the sequences from clone libraries include some clone sequences from Australian soils and a sequencing batch reactor (Liesack \& Stackebrandt, 1992; Bond et al., 1995). Eukaryotic organisms with an identical target site for probe PLA886 (b) in their 185 rRNA sequences are plants, fungi and diverse protists. present in the TUM rRNA database (Dr Ludwig, Technical University Munich) in July 1995. The set of data contained at this time 17 sequences of members of the order Planctomycetales. For probe design the respective tool from the ARB software package (O. Strunk \& W. Ludwig, Technical University Munich, Germany; URL: http://www.biol.chemie.tu-muenchen.de/pub/ ARB) was used. Two target regions for oligonucleotide probes were found to be highly diagnostic for the members of the Planctomycetales covering nucleotide positions 46-63 (E. coli numbering; Brosius et al., 1981) and 886-904, respectively. The probes were named PLA46 and PLA886. The former region around helices 4 and 5 has been used as target site for identification of planctomycetes already by Liesack \& Stackebrandt (1992). Another probe specific for planctomycetes and some other bacteria targeting a further region of the $16 \mathrm{~S}$ rRNA has additionally been reported (Fuerst et al., 1997). Meanwhile, the number of available $16 \mathrm{~S}$ rRNA sequences for the Planctomycetales has increased markedly to 75 full or partial sequences (TUM rRNA database, August 1997). However, applying recent sequence checks both probes are still targeting all planctomycete sequences except four partial sequences from 16S rDNA clones (Bond et al., 1995) for PLA46 and one nearly complete sequence from an isolate (Ward et al., 1995) for PLA886. However, both probes recognize no sequences from any other prokaryotes (recent probe check against Ribosomal Database Project data release 7.0, July 1998; Maidak et al., 1997), therefore confirming the uniqueness of both target regions for the planctomycetes. The results of the alignment checks are displayed in Fig. 1. Surprisingly, inclusion of $18 \mathrm{~S}$ rRNA sequences in the probe checks showed that some groups of eukaryotes possess the identical target region for probe PLA886. Plants, fungi and some protists like Acanthamoeba spp., Cryptosporidium spp. or Toxoplasma spp. belong to these groups, which, however, do not form a monophyletic cluster within the domain Eucarya.

\section{Optimization of hybridization conditions}

The aim of probe development was single cell identification by in situ hybridization in environmental samples. Therefore, specificity of both probes was tested directly by whole-cell hybridization with fluorochrome-labelled probes and representative reference organisms. All six tested planctomycetes, which represent the four lineages and include four pigmented strains, showed no considerable autofluorescence and yielded strong hybridization signals with both oligonucleotide probes. Gemmata sp. SCH633 disp.ayed the most uniform signals. 


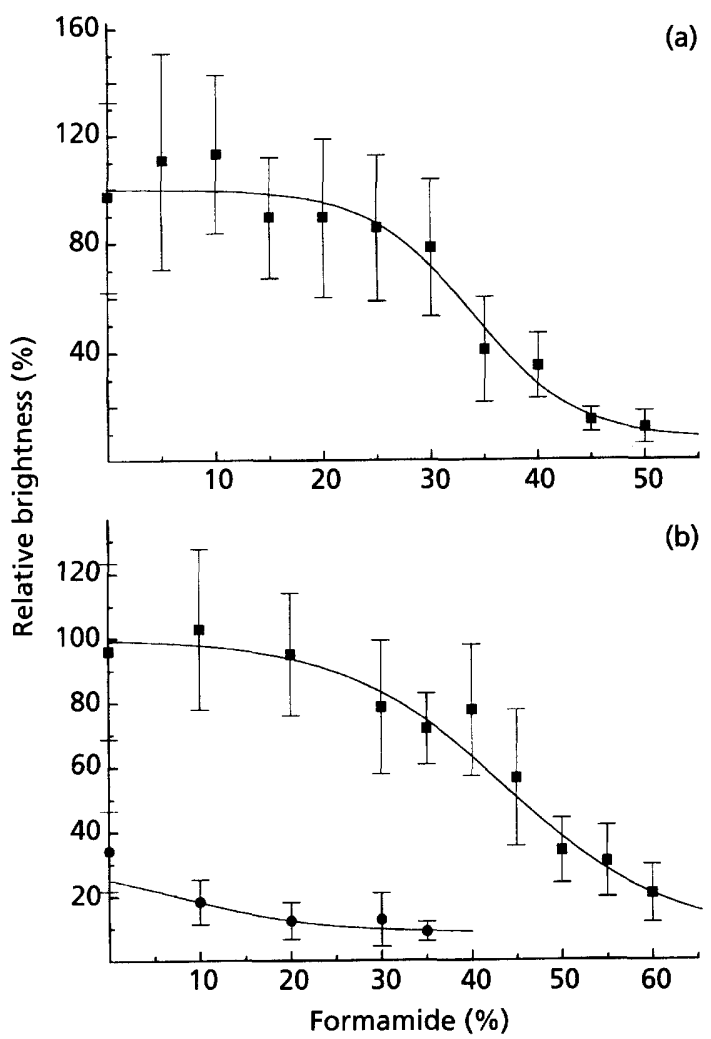

Fig. 2. Probe-binding profiles of probes PLA46 and PLA886. The relative strength of hybridization was determined at increasing concentrations of formamide by quantification of intensities of the fluorescence signals. Graphs show results for probe PLA46TAMRA (a) against Gemmata sp. strain SCH633 and probe PLA886-TAMRA (b) against Gemmata sp. strain SCH633 ( $)$ and $B$. linens DSM $20425^{\top}$ (O). Hybridizations with PLA886 were done with an equimolar amount of competitor CPLA886. The mean fluorescence intensity of probe-positive cells after hybridization at $0 \%$ formamide was defined as $100 \%$. Single data points mark arithmetic means \pm SD.

Therefore, optimal hybridization stringencies were evaluated with this strain in formamide series by quantification of fluorescence intensities (Fig. 2).

Probe PLA46 yielded strong signals up to $30 \%(\mathrm{v} / \mathrm{v})$ formamide followed by a significant decline at $35 \%$ (v/v) formamide. Chryseobacterium gleum LMG 8333 with four base changes within the target strand was the reference strain tested showing the highest sequence similarity (see Fig. 1a). Cells of this organism displayed no signals even without formamide in the hybridization buffer. Considering strength and position of the mismatches in other non-target organisms which were not available for specificity testing, such as, e.g. spirochaetes, a formamide concentration of $30 \%(\mathrm{v} / \mathrm{v})$ was chosen as optimal stringency for PLA46. Members of the genus Chlamydia contain only one weakly discriminating base change at position 5 of the target region (position 50 in E. coli numbering). It is probable that this mismatch could not be discriminated at the applied stringency of $30 \%(\mathrm{v} / \mathrm{v})$ formamide. Therefore, it is assumed that Chlamydia spp. could also be detected with probe PLA46. For probe PLA886 preliminary experiments indicated that an unlabelled competitor oligonucleotide, cPLA886, always has to be used to effectively prevent hybridization of PLA886 to some actinomycetes and other outgroup bacteria (for details see Fig. 1b). PLA886 has only one central C-A mismatch with such non-target sequences, which is insufficient for full discrimination without a competitor able to capture the $16 \mathrm{~S}$ rRNAs of these organisms. At a formamide concentration of $35 \%(\mathrm{v} / \mathrm{v})$ and an equimolar amount of cPLA886 signals of the non-target reference $B$. linens were decreased to the low level of autofluorescence, while Gemmata sp. SCH633 still yielded strong signals. Therefore, $35 \%(\mathrm{v} / \mathrm{v})$ formamide was set as optimal hybridization stringency for PLA886.

At the optimized hybridization conditions all six reference strains showed strong signals with both PLA probes, whereas all tested organisms from other bacterial phyla displayed no fluorescence signals.

\section{In situ detection in different habitats}

Fixed samples originating from different habitats were probed with PLA46 and PLA886. The results displayed in Table 3 show that members of the Planctomycetales could be found in nearly all examined samples. Estimated fractions, relative to DAPI counts, ranged from the presence of only single cells to significant numbers of approximately $5 \%$ of all cells. In all examined samples the planctomycetes were mainly attached to particulate matter or cell clusters. Activated sludge was examined extensively as an example of a highly diverse ecosystem. Two successive hybridizations with PLA886 and PLA46 labelled with different fluorochromes allowed the determination of the degree of accordance between the cells detected with each of the two probes. The fraction of double-stained cells was usually above $95 \%$ (Table 3 and Fig. 3a).

Planctomycetes in activated sludge occurred mainly as single spherical or ovoid cocci with diameters between 1.0 and $2.5 \mu \mathrm{m}$. Cells were located mostly within or at the edge of sludge flocs and in particular attached to filaments (see Fig. 3a), but seemed to be randomly distributed in the sample material. This distribution pattern could be observed in all 27 activated sludge samples analysed. The relative quantities of planctomycetes differed significantly between sewage treatment plants. A marked difference in abundance could be observed even between the two stages of the highcapacity municipal plant München-Großlappen. In the first stage with a load value of approximately $200 \mathrm{mg}$ BOD $_{5} 1^{-1}$ always less than $0.1 \%$ of DAPI-positive cells reacted with the PLA probes. However, in the second stage with a load of $20 \mathrm{mg} \mathrm{BOD}_{5} \mathrm{l}^{-1}$ approximately $2-5 \%$ of all cells were probe-positive. Relative enrichment of planctomycetes in the second stage is striking and suggests a possible role of this group in the degradation of more recalcitrant compounds. 
Table 3. Microscopic analysis of environmental samples for the presence of planctomycetes by probing with PLA46 and PLA886

\begin{tabular}{|c|c|c|c|}
\hline Sample* & $\begin{array}{l}\text { Microscopic appearance of the } \\
\text { detected planctomycete population }\end{array}$ & Abundance $\dagger$ & Accordance $\neq$ \\
\hline $\begin{array}{l}\text { Lagoon and outflow } \\
\text { channel to the sea }(7)\end{array}$ & $\begin{array}{l}\text { Rosettes of ovoid cells, single cocci; budding } \\
\text { cells observable }\end{array}$ & $++/+++\mathbb{S}$ & ++ \\
\hline \multicolumn{4}{|l|}{ Activated sludge } \\
\hline Großlappen, stage II (4) & $\begin{array}{l}\text { Cocci of different size, sometimes in groups, } \\
\text { filaments of ovoid cells }\end{array}$ & +++ & +++ \\
\hline Dietersheim, stage I (3) & Cocci, single or in groups, few rods & ++ & + \\
\hline Dietersheim, stage II & Single cocci & ++ & + \\
\hline Valencia-Pinedo (2) & Mainly single cocci, sometimes in groups & ++ & ++ \\
\hline \multicolumn{4}{|c|}{ Other samples from WWTPs } \\
\hline Sand filter, Dietersheim & Cocci, thin filaments & ++ & ++ \\
\hline Influent, Valencia-Pinedo & Single cocci & + & + \\
\hline Effluent, Valencia-Pinedo & - & - & - \\
\hline
\end{tabular}

* See Table 1; numbers in parentheses indicate the number of samples examined from the respective habitat.

$\dagger$ Estimated fraction of PLA-positive cells relative to total cells visualized by DAPI staining. $+++, 0 \cdot 5-5 \%,++, 0 \cdot 1-0 \cdot 5 \% ;+,<0 \cdot 1 \%$; -, no positive cells detectable.

$\ddagger$ Fraction of PLA46 and PLA886 double-stained cells relative to all detected planctomycete cells. +++ , Only single cells not doublestained;,$++>99 \% ;+,>95 \%$.

$\$$ Different fractions of positive cells in the different samples examined.

Formation of rosettes as observed in the brackish lagoon Lake Albufera (Fig. 3b) has been described for members of the genera Planctomyces and Pirellula. The pearshaped cells displayed bright signals. The rosettes comprised around one-half of all planctomycetes in the lagoon samples. Some of the cells seemed to be in the state of budding. The samples contained significant numbers of phototrophic organisms displaying remarkable autofluorescence, especially in the red spectrum range. Clear identification with TAMRA-labelled probes was possible only using the HQ-Cy3 filter set, which enabled the differentiation of orange-yellowish hybridization signals and reddish background fluorescence, whereas the Zeiss filter set no. 15 was not appropriate for this differentiation based on colour.

PLA probes visualized cocci and thin filaments in biofilms from the sand filter of a WWTP. The examined sample originated from a layer within the filter bed where oxygen-free conditions prevail nearly all the time. Besides the discovery of planctomycete $16 \mathrm{~S}$ rDNA clone sequences in an anaerobic digester (Godon et al., 1997) this is to our knowledge the first report on observation of planctomycetes in an anoxic habitat. Meanwhile, probe PLA46 has also been used in a silty clay soil sample where planctomycetes were found to comprise a significant part of the bacterial population (Zarda et al., 1997).

\section{Lack of detectability of planctomycetes with the bacterial probe EUB338}

An interesting observation in this study was that all cells detected with the PLA probes showed only a very low to no hybridization signal with probe EUB338 (Fig. 3c). The lack of detectability with this frequently used bacterial probe is in accordance with available sequence information. All known planctomycete $16 \mathrm{~S}$ rRNA sequences show at least one base change within the target region of probe EUB338. Three of the four lineages (the Planctomyces, Pirellula and Gemmata lineages) even possess three base changes, two of which lead to strong mismatches. It is therefore by no means surprising that reference strains of planctomycetes as well as environmental populations are hardly detected with probe EUB338. The lack of hybridization with EUB338 can even be regarded as a third probe-based proof, besides 

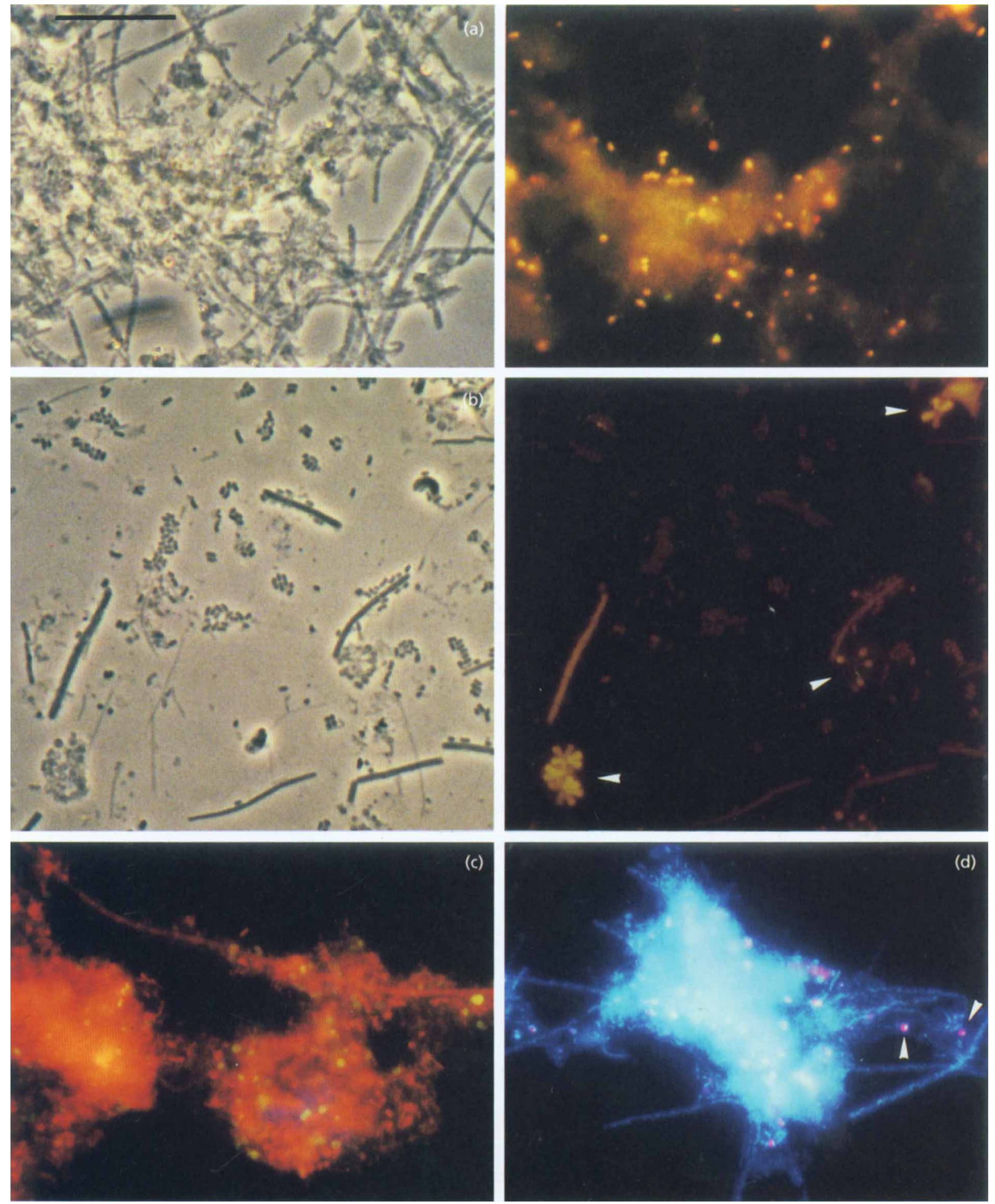

Fig. 3. Detection of planctomycetes in environmental samples. For (a) and (b), identical fields were viewed by phase-contrast (left) and epifluorescence (right) microscopy. (a) Hybridization of activated sludge from the WWTP Valencia-Pinedo with FLUOS-labelled probe PLA886 and TAMRA-labelled probe PLA46. The yellow colour in the double exposure indicates simultaneous binding of the green and the red-emitting probes. (b) Hybridization of a sample from the Albufera lagoon with TAMRAlabelled probe PLA46. Signals were detected with the HQ-Cy3 filter set. Typical rosette morphotypes are marked by arrowheads. (c) Lack of detectability of planctomycetes with bacterial probe EUB338. Hybridization of activated sludge with FLUOSlabelled probes PLA46 and PLA886 and TAMRA-labelled probe EUB338. Double exposure with fluorescein- and rhodaminespecific filter sets demonstrates that planctomycetes do not bind the bacterial probe. (d) Intracellular ultrastructure of planctomycetes. Hybridization of activated sludge with TAMRA-labelled probe PLA46 and counterstaining with DAPI. Double exposure with DAPI- and rhodamine-specific filter sets shows the concentration of DNA within the hybridized cells (arrowheads). All photomicrographs have been taken at $\times 1000$ magnification. Bar, $20 \mu \mathrm{m}$. 

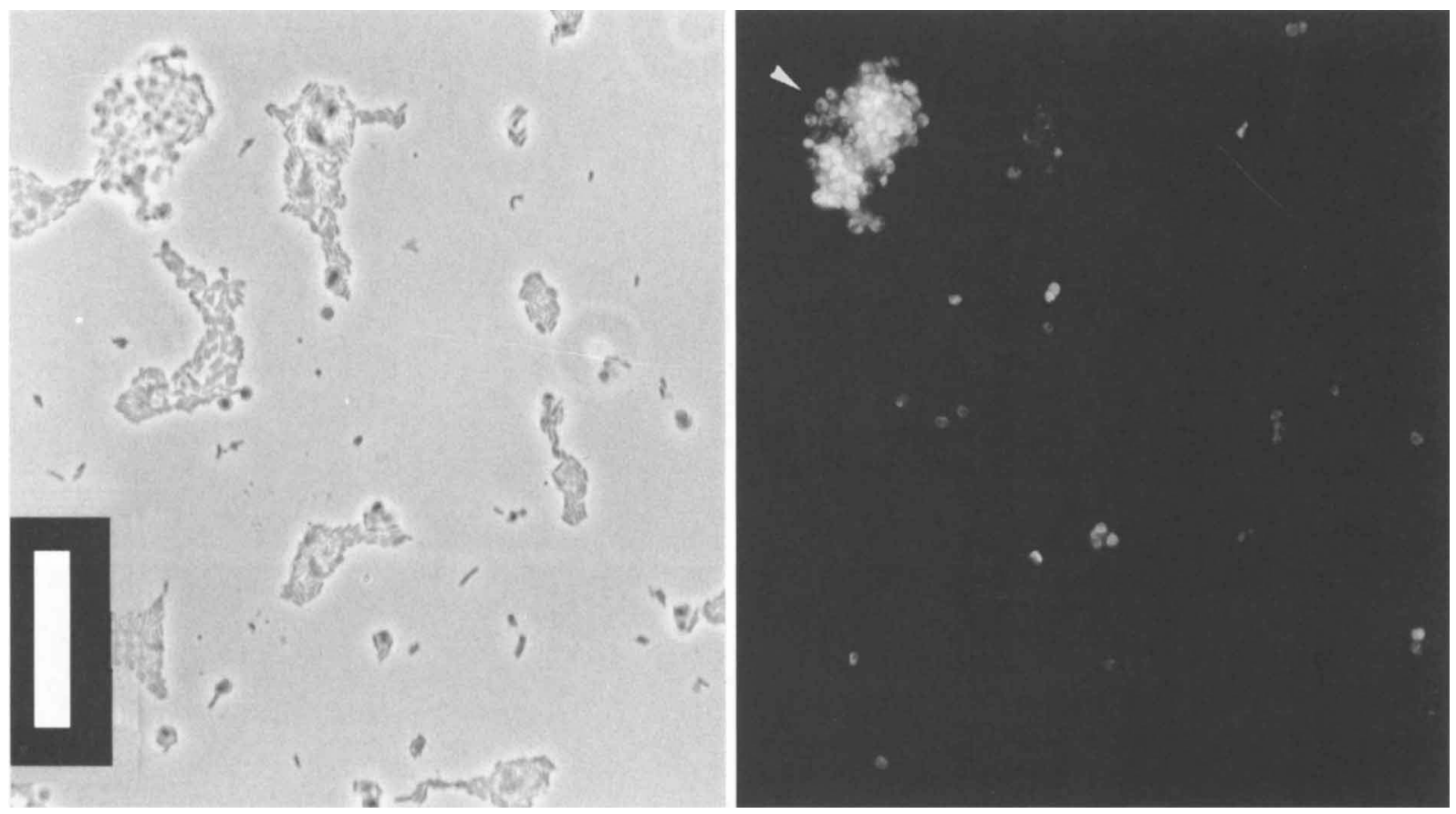

Fig. 4. Ring-shaped appearance of probe-conferred fluorescence in planctomycetes. Hybridization of an artificial mixture of cells of Gemmata sp. SCH633 and B. linens DSM 20425 $5^{\top}$ with FLUOS-labelled probe PLA886. Phase-contrast (left) and epifluorescence (right) micrographs show identical microscopic fields. Bar, $20 \mu \mathrm{m}$.

positive reaction with PLA46 and PLA886, for affiliation of the detected cells to the Planctomycetales. The lack of reaction with this most commonly used bacterial probe means that planctomycetes have not been recognized in probe-based in situ investigations yet. Consequently, the use of the PLA probes increases the fraction of bacteria which can be detected and classified by in situ hybridization with rRNA-targeted probes in environmental samples. For a bulk soil sample Zarda et al. (1997) have already shown that by combined use of EUB338 and PLA46 the total number of detectable bacteria could be increased from 40 to $47 \%$.

\section{Intracellular distribution of fluorescence signals in planctomycetes}

A second unusual observation was that for some of the planctomycete cells probe-conferred fluorescence was not distributed evenly across the whole cell body but was ring-shaped with a dark area in the centre of the cell, which seems to be free of ribosomes. Fig. 4 displays this character for cells of Gemmata sp. SCH633. In all examined environmental samples some of the planctomycetes showed such ring-shaped hybridization signals. Concomitantly with the structuring of the probeconferred signal a complementary distribution of DAPIconferred fluorescence was found. DAPI visualized the DNA, which was strongly concentrated at one spot in the middle or the edge of the cell body. Together DAPI and the probe-bound fluorochrome cover the whole cell body (Fig. 3d). Since reference cells show the same pattern of distribution of DNA and rRNA fluorescence this is regarded as a feature typical for planctomycetes. The observation could be nicely explained by the concentration of nuclear material in a distinct part of the cell, referred to as the nucleoid, which has been reported for pure cultures of Gemmata obscuriglobus (Franzmann \& Skerman, 1984), I. pallida (Staley et al., 1992) and recently two Pirellula species (Lindsay et al., 1997).

\section{Concluding remarks}

The two newly developed probes for planctomycetes extend the existing set of group-specific rRNA-targeted oligonucleotides on the phylum to subclass level for a rapid in situ classification of individual bacterial cells (Amann et al., 1995). Combined application of both PLA probes ensured reliable in situ identification in environmental samples by double staining of phylum members. In situ analysis demonstrated the presence of planctomycetes in a variety of habitats and revealed marked differences in abundance despite widely similar morphotypes of the detected cells. The probes allow the examination of the abundance of planctomycetes in habitats from which they have already been isolated or shown to be present by PCR-based methods. Furthermore, they enable one to check identity of cells which have been solely observed by phase-contrast microscopy and affiliated by morphology but not successfully isolated such as diverse Planctomyces species (Staley et 
al., 1992). Probing may therefore assist isolation of these fastidious organisms and could be helpful to close the gap between the molecular information obtained in recent years and the existing knowledge about the organisms themselves.

\section{ACKNOWLEDGEMENTS}

We are grateful to Markus Schmid and Sibylle Schadhauser for excellent technical assistance and to Rosa Aznar, Robert Erhart and Margareta Junkermann for providing sample material and reference cells. This work was supported by the Deutsche Forschungsgemeinschaft (grant Am 73/2-3).

\section{REFERENCES}

Alm, E. W., Oerther, D. B., Larsen, N., Stahl, D. A. \& Raskin, L. (1996). The oligonucleotide probe database. Appl Environ Microbiol 62, 3557-3559.

Amann, R. I., Binder, B. J., Olson, R. J., Chisholm, S. W., Devereux, R. \& Stahl, D. A. (1990). Combination of $16 \mathrm{~S}$ rRNA-targeted oligonucleotide probes with flow cytometry for analyzing mixed microbial populations. Appl Environ Microbiol 56, 1919-1925.

Amann, R., Ludwig, W. \& Schleifer, K. H. (1995). Phylogenetic identification and in situ detection of individual microbial cells without cultivation. Microbiol Rev 59, 143-169.

Aznar, R., Amaro, C., Garay, E. \& Alcaide, E. (1991). Physicochemical and bacteriological parameters in a hypereutrophic lagoon (Albufera lake, Valencia, Spain). Zentbl Mikrobiol 146, 311-321.

Bomar, D., Giovannoni, S. \& Stackebrandt, E. (1988). A unique type of eubacterial $5 \mathrm{~S}$ rRNA in members of the order Planctomycetales. J Mol Evol 27, 121-125.

Bond, P. L., Hugenholtz, P., Keller, J. \& Blackall, L. L. (1995). Bacterial community structures of phosphate-removing and nonphosphate-removing activated sludges from sequencing batch reactors. Appl Environ Microbiol 61, 1910-1916.

Borneman, J., Skroch, P. W., O'Sullivan, K. M., Palus, J. A., Rumjanek, N. G., Jansen, J. L., Nienhuis, J. \& Triplett, E. W. (1996). Molecular microbial diversity of an agricultural soil in Wisconsin. Appl Environ Microbiol 62, 1935-1943.

Brosius, J., Dull, T. L., Sleeter, D. D. \& Noller, H. F. (1981). Gene organization and primary structure of a ribosomal RNA operon from Escherichia coli. J Mol Biol 148, 107-127.

DeLong, E. F., Franks, D. G. \& Alldredge, A. L. (1993). Phylogenetic diversity of aggregate-attached vs. free-living marine bacterial assemblages. Limnol Oceanogr 38, 924-934.

Franzmann, P. D. \& Skerman, V. B. D. (1984). Gemmata obscuriglobus, a new genus and species of the budding bacteria. Antonie Leeuwenhoek 50, 261-268.

Fuerst, J. A. (1995). The planctomycetes: emerging models for microbial ecology, evolution and cell biology. Microbiology 141, 1493-1506.

Fuerst, J. A., Gwilliam, H. G., Lindsay, M., Lichanska, A., Belcher, C., Vickers, J. E. \& Hugenholtz, P. (1997). Isolation and molecular identification of planctomycete bacteria from postlarvae of the giant tiger prawn, Penaeus monodon. Appl Environ Microbiol 63, 254-262.

Giovannoni, S. J., Schabtach, E. \& Castenholz, R. W. (1987).
Isosphaera pallida gen. nov. and comb. nov., a gliding, budding eubacterium from hot springs. Arch Microbiol 147, 276-284.

Godon, J.-J., Zumstein, E., Dabert, P., Habouzit, F. \& Moletta, R. (1997). Molecular microbial diversity of an anaerobic digestor as determined by small-subunit rDNA sequence analysis. Appl Environ Microbiol 63, 2802-2813.

Gray, J. P. \& Herwig, R. P. (1996). Phylogenetic analysis of the bacterial communities in marine sediments. Appl Environ Microbiol 62, 4049-4059.

Hicks, R., Amann, R. I. \& Stahl, D. A. (1992). Dual staining of natural bacterioplankton with 4',6-diamidino-2-phenylindole and fluorescent oligonucleotide probes targeting kingdom-level $16 \mathrm{~S}$ rRNA sequences. Appl Environ Microbiol 58, 2158-2163.

Holt, J. G., Krieg, N. R., Sneath, P. H. A., Staley, J. T. \& Williams, S. T. (1994). Bergey's Manual of Determinative Bacteriology, 9th edn. Baltimore: Williams \& Wilkins.

Lee, S.-Y., Bollinger, J., Bezdicek, D. \& Ogram, A. (1996). Estimation of the abundance of an uncultured soil bacterial strain by a competitive quantitative PCR method. Appl Environ Microbiol 62, 3787-3793.

Liesack, W. \& Stackebrandt, E. (1989). Evidence for unlinked $r r n$ operons in the planctomycete Pirellula marina. J Bacteriol 171, 5025-5030.

Liesack, W. \& Stackebrandt, E. (1992). Occurrence of novel groups of the domain Bacteria as revealed by analysis of genetic material isolated from an Australian terrestrial environment. $J$ Bacteriol 174, 5072-5078.

Lindsay, M. R., Webb, R. I. \& Fuerst, J. A. (1997). Pirellulosomes: a new type of membrane-bounded cell compartment in planctomycete bacteria of the genus Pirellula. Microbiology 143, 739-748.

Maidak, B. L., Olsen, G. J., Larsen, N., Overbeek, R., McCaughey, M. J. \& Woese, C. R. (1997). The RDP (Ribosomal Database Project). Nucleic Acids Res 25, 109-111.

Neef, A., Zaglauer, A., Meier, H., Amann, R., Lemmer, H. \& Schleifer, K. H. (1996). Population analysis in a denitrifying sand filter : conventional and in situ identification of Paracoccus spp. in methanol-fed biofilms. Appl Environ Microbiol 62, 4329-4339.

Schlesner, H. (1986). Pirella marina sp. nov., a budding, peptidoglycan-less bacterium from brackish water. Syst Appl Microbiol 8, 177-180.

Schlesner, H. (1994). The development of media suitable for the microorganisms morphologically resembling Planctomyces spp., Pirellula spp., and other Planctomycetales from various aquatic habitats using dilute media. Syst Appl Microbiol 17, 135-145.

Schlesner, H. \& Stackebrandt, E. (1986). Assignment of the genera Planctomyces and Pirella to a new family Planctomycetaceae fam. nov. and description of the order Planctomycetales ord. nov. Syst Appl Microbiol 8, 174-176.

Schmidt, J. M. (1978). Isolation and ultrastructure of freshwater strains of Planctomyces. Curr Microbiol 1, 65-70.

Stackebrandt, E., Ludwig, W., Schubert, W., Klink, F., Schlesner, H., Roggentin, T. \& Hirsch, P. (1984). Molecular genetic evidence for early evolutionary origin of budding peptidoglycan-less eubacteria. Nature 307, 735-737.

Staley, J. T., Fuerst, J. A., Giovannoni, S. \& Schlesner, H. (1992). The order Planctomycetales and the genera Planctomyces, Pirellula, Gemmata, and Isosphaera. In The Prokaryotes, 2 nd edn, vol. IV, pp. 3710-3731. Edited by A. Balows, H. G. Trüper, M. Dworkin, W. Harder \& K. H. Schleifer. New York: Springer.

Trebesius, K., Amann, R., Ludwig, W., Muhlegger, K. \& Schleifer, K. H. (1994). Identification of whole fixed bacterial cells with non- 
radioactive $23 \mathrm{~S}$ rRNA-targeted polynucleotide probes. Appl Environ Microbiol 60, 3228-3235.

Wagner, M., Amann, R., Lemmer, H. \& Schleifer, K. H. (1993). Probing activated sludge with proteobacteria-specific oligonucleotides: inadequacy of culture-dependent methods for describing microbial community structure. Appl Environ Microbiol 59, 1520-1525.

Ward, N., Rainey, F. A., Stackebrandt, E. \& Schlesner, H. (1995). Unraveling the extent of diversity within the order Planctomycetales. Appl Environ Microbiol 61, 2270-2275.

Ward-Rainey, N., Rainey, F. A., Wellington, E. M. H. \& Stackebrandt, E. (1996). Physical map of the genome of Planctomyces limnophilus, a representative of the phylogenetically distinct planctomycete lineage. J Bacteriol 178, 1908-1913.

Woese, C. R. (1987). Bacterial evolution. Microbiol Rev 51, 221-271.

Zarda, B., Hahn, D., Chatzinotas, A., Schönhuber, W., Neef, A., Amann, R. \& Zeyer, J. (1997). Analysis of bacterial community structure in bulk soil by in situ hybridization. Arch Microbiol 168, 185-192.

Received 14 April 1998; revised 20 August 1998; accepted 24 August 1998. 